\title{
Situational analysis of physical education among public primary schools in Côte d'Ivoire
}

Ayekoe S. ${ }^{1}$, Lang C. ${ }^{2 *}$, Traoré S. G. ${ }^{3,4}$, Utzinger J. ${ }^{5}$, Gerber M. ${ }^{2}$, Long K. Z. ${ }^{5}$, Pühse, U. ${ }^{2}$, Dao D. ${ }^{3,6}$, and Bonfoh B. ${ }^{3}$

${ }^{I}$ Institut National de la Jeunesse et des Sports (INJS), Abidjan, Côte d'Ivoire, ${ }^{2}$ Department of Sport, Exercise and Health, Sport Science Section, University of Basel, Basel, Switzerland, ${ }^{3}$ Centre Suisse de Recherches Scientifiques en Cote d'Ivoire, Abidjan, Côte d'Ivoire, ${ }^{4}$ Université Peleforo Gon Coulibaly, Korhogo, Côte d'Ivoire, ${ }^{5}$ Swiss Tropical and Public Health Institute, Basel, Switzerland, ${ }^{6}$ Université Felix Houphouët-Boigny, Abidjan, Côte d'Ivoire,

*Corresponding author: Christin Lang, $\mathrm{PhD}$, Department of Sport, Exercise and Health, University of Basel, Switzerland, Birsstrasse 320B, 4052 Basel, Switzerland, Email: christin.lang@unibas.ch.

Conflict of interest

The authors have no conflict of interest.

Acknowledgements

We thank the Foundation Botnar for funding the KaziAfya study (grant number: 6071). The authors acknowledge support from the DELTAS Africa Initiative [Afrique One-ASPIRE /DEL15-008]. We are grateful to parents, coaches, principals and teachers. We would like to thank the Inspector, the authorities of Taabo and all people who were willing to support and participate in this study.

Word count: 5560 


\section{Situational analysis of physical education among public primary schools in Côte d'Ivoire}

Background. Physical activity is known to improve health and cognitive function in children. Yet, in Côte d'Ivoire, physical education (PE) receives little attention in the current school curricula due to insufficient time allocation, lack of fresh-up training for teachers, as well as insufficient governmental financial contribution towards school infrastructure, materials and sport facilities.

Objective. In the frame of the implementation of a randomized-controlled trial, in which we will examine the effects of a school-based physical activity and multimicronutrient supplementation intervention on primary school children in Côte d'Ivoire, we carried out a situational analyses of PE in eight randomly selected public primary schools in Taabo, Côte d'Ivoire, from November 2019 to March 2020 in advance.

Methods. First, the study comprised a systematic observation of the school environment. Second, guided interviews were conducted with the Inspection of the Ministry of National Education of Taabo, and the general inspectorate of national education in charge of PE and sport at Abidjan. The primary focus in these interviews was placed on primary school organization, training of teachers, time allocated to PE in the official schedule, as well as monitoring and evaluation of the PE curriculum. Third, eight focus group discussions (FGDs) were conducted with 40 teachers and 8 school principals focusing on the PE program, teacher's perception and motivation towards teaching PA. Fourth, we carried out cost analysis to estimate the required financial resources for basic school infrastructure (sport fields), teacher salary and consumables, sport materials and equipment, which are required to meet minimal standards for implementing quality PE at public primary schools in rural Côte d'Ivoire. Last, we implemented a participatory dialog with an educational inspector, school teachers and principals to improve the situation of PE in Taabo. FGD transcriptions were transferred to MAXQDA for analysis.

Results. In line with the national curricula, teachers perceive PE to be important for children's motor and social learning. Despite this importance, PE remains a neglected school subject. The main reasons stated were (i) significant reduction 
of PE lessons per week in favour of academic subjects, (ii) lack of training, (iii) insufficient sports facilities and equipment, and (iv) absence of an evaluation guideline on how to grade a child`s PE performance. Our financial appraisal reveals that a minimum investment of FCFA 2'710'000 ( US \$ 5'000) per school is needed to establish a basic infrastructure at each school and to empower teachers to conduct standardised and quality PE in this area.

Discussion. The promotion of PE is currently not a key educational target in Côte d'Ivoire. Thus, the neglected importance at national level perpetuates the marginalized status of PE. Overall, teachers claim that the lack of support in a setting without proper facilities, equipment, and personal skills hampers their motivation to implement PE.

Conclusion. In order to initiate a change to the current situation, evidence on the overall health benefits and academic performance of regular physical activity among primary school children is urgently needed to highlight the importance of this neglected school subject to education authorities

Keywords: Children; curriculum; physical activity; teacher training, WestAfrican education system

\section{Introduction}

In recent years, research has clearly established a strong association between health and education. Children who regularly practice sport are those who have the best level of fitness, who have better cognitive function, perform better in school and enjoy better health (Donelly et al. 2016; Sibley and Etnier 2003; Ludyga et al., 2016; Trudeau and Shephard 2008). Physical activity in early life optimizes brain functions that involve memory and influences individuals' learning capacity throughout the life span (Kempermann 2008; Ludyga, Gerber, Pühse, Looser, Kamijo 2020; Ludyga et al. 2016; Macpherson, Schneider, and Smith 2017). In contrast, childhood physical inactivity is an independent risk factor for Non-Communicable Diseases (NCDs), which can lead to poor health outcomes in later life (Walter, du Randt, and Venter 2011). Sedentary 
behaviours are associated with chronic, but preventable diseases such as obesity, coronary diseases and diabetes (Martyniuk and Tucker 2014).

Physical education (PE) is one of a number of means to accumulate the recommended level of 60 minutes physical activity per day for children aged 5-17 years (WHO 2020). However, PE aims to develop physically literate individuals to pursue a lifelong healthy active lifestyle through well-designed learning tasks that promote the required knowledge and skill acquisition (Couturier, Chepko, and Hale 2014). Promotion of PE further provides children with experiences that allow them to cope with challenges they face across the life span (Donelly et al. 2016). However, most of the studies reporting the beneficial effects of PA have been conducted on populations from high-income countries. Fewer studies have addressed the status and impact of physical activity on children`s health in low-to-middle income countries. Among the few, the 'Disease, Activity and Schoolchildren's Health' (DASH) project implemented a PE-based health intervention to increase health literacy among South African primary schoolchildren from marginalized schools. Findings from the project suggest that increased levels of habitual physical activity were associated with higher health-related quality of life (Salvini et al. 2018), with lower risks of obesity and hypertension, but increased risk for soil-transmitted helminth infections (Gerber et al. 2018). Further results of this study showed a small, but significant decrease in body mass index (BMI) for children taking part in the structured PE program (Müller et al. 2019). Moreover, the program had a positive impact on academic performance within one year (Gall et al. 2020).

Likewise, in Côte d'Ivoire, school is recognized as the main place of education and training of young people. Thus, the essential mission of education is to provide values and knowledge to children by focusing on three domains: cognitive, emotional 
and psychomotor functions (Hoque 2016). According to the Ministry of National Education of Côte d'Ivoire, school is the place where

"[...] human values, essential for the harmonious development of a nation, are forged. It must indeed be the privileged framework where the search for truth, intellectual rigor, respect for oneself, for others and for the nation, love for the nation, the spirit of solidarity, initiative, creativity and responsibility is cultivated." (Bini 2016)

PE takes place in the country's schools and sports training centres (sport stadiums) under the authority of different ministries (Ministry of Sport, Ministry of National Education, Ministry of Higher Education and Scientific Research). In Côte d'Ivoire, the teaching of PE is compulsory in primary and secondary school, according to the Decree No. 98-332. Ministries are obliged to implement PE in primary and secondary schools, equivalent to all other academic subjects, whereas it is optional at university level (Bini 2016). PE in primary school is part of the overall curriculum that is taught by a single teacher. However, it remains upon the decision and perceived importance of the supervising institution, whether and how many school hours are allocated to each school subject.

The general objectives related to teaching PE in Côte d'Ivoire are (i) basic motor education, (ii) hygiene and health through increased physical abilities, (iii) knowledge of the surrounding physical world and greater control of reality and acquisition of the qualities of action, adaptation and communication with the environment necessary for self-expression. More recently, Title I of Law No. 2014-856 (22 December 2014) underlines that the practice of physical activities and sports is a right recognized for all segments of the population, regardless of age, sex, race, religion, or physical and mental condition, under the conditions defined by law. 
Despite the specifications in the official documents that designate PE as a compulsory school subject in Côte d'Ivoire, its legitimacy and relevance is still debated within schools. The low implementation rate of PE mirrors the little space allocated to this school subject in the overall curriculum (GPE 2018). One reason might be that until now, very few scientific studies have been conducted to assess the effectiveness of PE in the education system in Côte d'Ivoire. Accordingly, little is known about the state and status of PE in Côte d'Ivoire, with no solid evidence existing on a local/national level that could be used to convince authorities, teachers and parents about the relevance of PE in schools. In 2016, a study on the marginalization of PE and sports as a school subject was carried out in private and public secondary schools in the commune of Abobo in Côte d'Ivoire. The study confirmed the critical situation of PE in Côte d'Ivoire, as school administrations, teachers, parents and schoolchildren perceived the subject as a mere game to have fun, a hobby practiced during free time without academic value (Bini 2016).

Given this background, the purpose of the present study is to provide a situational analysis of the state and status of PE among public primary schools in the municipality of Taabo, a typical small to medium sized town located in the interior of Côte d'Ivoire. A special focus will be placed on time allocation, facilities, motivation of teachers and hindering factors. The purpose of this situational analysis is to establish the base for the planned implementation of a multi-country randomized-controlled trial (Gerber et al. 2020), in which we will examine the effects of a school-based physical activity and multi-micronutrient supplementation intervention on primary schoolchildren's growth, health and wellbeing in Côte d'Ivoire, Tanzania, and South Africa. Essentially, the acquired knowledge from the present paper will be conducive to identify key stakeholders and barriers to implement the PE curriculum in the local 
setting. Key stakeholders will be of particular importance to support the implementation process of the planned trial (KaziAfya) and to develop a theory of change (Oberlack et al. 2019), which will be used to disseminate the insights gained from the KaziAfya trial.

\section{Methods}

\section{Demographics}

Information for the present situational analyses was collected in eight public primary schools randomly selected in Taabo city and village from the Health and Demographic Surveillance System Taabo (HDSS) in November 2019. Taabo is located in the region of Agneby-Tiassa, in South-central Côte d'Ivoire, about $150 \mathrm{~km}$ Northwest of the economic capital Abidjan and $60 \mathrm{~km}$ South of Yamoussoukro, the political capital of

Côte d'Ivoire (Figure 1). The Taabo site was chosen because it houses a Primary Education Inspectorate and a demographic and health surveillance system that includes 13 villages and more than 100 hamlets. The total population covered by the HDSS is approximately 42,480 inhabitants from 6,707 households under surveillance. The Taabo HDSS is a research platform for different backgrounds, disciplines and cultures (Koné S 2015).

The eight involved public primary schools in Taabo, Côte d'Ivoire are partner schools that will participate in the aforementioned KaziAfya intervention trial (Gerber et al 2020). In total, from the eight schools, approximately 1,320 children from grade 14 (5-12 years old) will be included. Moreover, 40 teachers, eight school principals and one education inspector are involved in the implementation of the intervention trial.

\section{Qualitative data collection and analysis}

All interviews were conducted in French language (official language in Côte d'Ivoire) 
based on a semi-structured interview guide. Participants provided informed consent and were willing to participate in the focus group discussions (FGDs).

In a first step, we carried out a systematic observation of the school environment by PE experts and epidemiologists involved in the randomized-controlled trial. Second, the district educational inspector of Taabo and a respondent at the General Inspectorate of National Education in charge of PE and sport at Abidjan were interviewed on (i) primary school organization, (ii) teacher training, (iii) monitoring and evaluation of the PE program and teaching staff, and (iv) time allocated to PE in the official timetable. Third, we conducted eight FGDs, one at each school. Each FGD involved four class teachers (one teacher per grade level) and the school principals from each school (Gerber et al. 2020). Fourth, we carried out a participatory financial appraisal to estimate the required financial resources for school infrastructures (sports field), teacher salary and consumables, sport materials and equipment that is required to meet minimal standards for implementing quality PE at public primary schools in Taabo.

Lastly, we implemented a participatory dialog with educational inspector, school teachers and principals to improve the situation of PE. This dialog included: (i) negotiation of one additional weekly PE lesson with; (ii) motivated teachers (financial incentive), (iii) recruitment of graduated secondary PE teachers to train and support primary school teachers to implement PE at their school, (iv) supply basic sports equipment for a class of 50 children (e.g., football, handballs and tennis balls, skipping rope), (v) provision of hygiene kits to schools and the inspectorate to fight infectious diseases, including COVID19 and (vi) landscaping and maintenance for sport fields on the school grounds.

The FDGs were conducted in French language by a social scientist serving as a moderator and assisted by an observer for note taking and reporting. After seeking 
informed consent of the participants, each FGD of approximately 40 minutes was recorded, using a digital voice recorder. Data recorded during interviews were systematically transcribed into Microsoft Word (Microsoft Corporation, Redmond,WA, USA). The transcripts were then analysed using MAXQDA software V18 (Verbi GmbH, Berlin, Germany) by codifying data according to a list of codes elaborated from the main ideas emerging from the transcriptions (Traoré et al. 2018). The codes were then narrowed to four themes for content analysis: (i) the situation of teaching PE in public primary schools in the municipality of Taabo, (ii) teachers' perception on the importance of teaching PE and (iii) barriers to actually implement PE with their class.

\section{Ethical consideration}

The study was carried out under the approval of the national ethics committee of Public Health and Hygiene in Côte d'Ivoire, whose reference is as follows: 100-18 / MSHP / CNS VS-km. We also obtained a research authorization from the Ministry of Higher Education and Research in Côte d'Ivoire.

All study procedures are in line with the ethical principles for medical research described in the current version of the Declaration of Helsinki. 


\section{Results}

\section{Systematic observation of the school environment in Taabo}

The eight selected public primary schools are part of a randomized-controlled trial, aiming to examine the effects of a school-based PE and multi-micronutrient supplementation intervention on health and cognitive functioning. Each school consists of two buildings. Half of the schools have no electricity and only one school is fenced in. For PE, there are no indoor facilities, including changing rooms and showers. There is no groundskeeper to maintain the sports field and the ground is accessible to the public. Four schools share a sports ground for PE.

\section{Structure and timetable of PE in primary schools}

In the Ivorian education system, primary school is under the Ministry of National Education and includes preschool and elementary school levels. The preschool level covers three sections: the small section, the middle section and the large section. Elementary school includes six levels: the 1st and 2nd year is labelled as "preparatory course" (CP1 and CP2), the 3rd and 4th year are labelled as "elementary course" (CE1 and CE2), the 5th and 6th year are labelled as "middle course" (CM1 and CM2). At the end of primary school, students receive the Certificate of Primary and Elementary Studies (CEPE). In 2014, statistics from the Ministry of National Education, Technical Education and Vocational Training (MENET) show that the gross rate of primary school enrolment is $94.7 \%$. The rate is higher for boys (99.7\%) than for girls $(89.6 \%)$. According to the official regulations, all school subjects (oral expression, written expression, grammar, spelling, vocabulary, reading, PE, mathematics, science, geography, history music, art, dancing, etc.) are provided as coeducational classes and are taught by the same teacher. The performance of schoolchildren is annually evaluated 
for each school subject, except for PE. Only schoolchildren of grade 6 (CM2) are assessed in PE to obtain their Certificate of Primary and Elementary Studies (CEPE). Table 1 and Table 2 provide an overview of the total hourly volume per lesson in the official timetable of grade 1 (CP1) for the academic year 2018/2019 and the academic year 2019/2020.

In the past, schoolchildren with disabilities, particularly when visiting a mainstream school, were excluded from weekly PE lessons. In recent years, however, the Ivorian education system has evolved towards a more inclusive physical and sports education, moving away from the generally widespread notion of "disability", towards a concept of "partial incapacity". Today, it is recommended that schoolchildren with disabilities participate in PE lessons by taking specific social roles, such as referees, judges, officials, timekeeper, etc.

\section{Teachers training and capacity development}

Primary school teachers are responsible for the implementation of all curriculum subjects, including PE. In Côte d'Ivoire, the training of preschool and public primary school teachers is provided by the 14 Aptitude and Pedagogical Training Centers (CAFOP). Before 2013, admission to the CAFOPs was made with the BEPC (first diploma of general secondary school) for the training of assistant teachers and with the BAC (last diploma of general secondary school) for the training of ordinary teachers through direct competitions organized by the Examinations and Competitions Department (DECO). Since 2013, after the civil crisis, the new government decided that the admission to the CAFOPs will be made only with the BEPC (first diploma of general secondary school) for the training of assistant teachers. The training period lasts two years. The first year is completed within the CAFOPs and lasts for approximately thirty weeks over two periods of theoretical training, alternated by two supervised 
practical training courses of 21 days each in a primary school. After completion of the first year, students obtain a Diploma of Trainee Teacher. Teaching PE is part of the CAFOPs and student teachers must acquire knowledge and skills enabling them to (i) build and develop attitudes and skills in PE, and (ii) use different teaching methodologies/pedagogical approaches to facilitate motor learning in PE. The second year of training is conducted as an internship at a public primary school, before being promoted as an assistant teacher.

In Côte d'Ivoire, the Department of Pedagogy and Continuing Education of the Ministry of National Education, Technical Education and Professional Training is in charge of the institution for monitoring and evaluating school programs. The monitoring and evaluation of a student teacher is conducted by educational supervision of (i) the school's director, (ii) the educational advisor and (iii) the primary education inspector of relevant primary school. The student teacher has to hold a lesson in French, Mathematics, Expression and Creation Activities or PE.

\section{PE curriculum time allocation}

The school's timetable for each class level, and thus the day, time and duration of PE, is set by the Ministry of National Education. Compared to 2018 and 2019, available data of 1985 and 1988 document the change of time dedicated to PE according to the Law $\mathrm{n}^{\circ}$ 85-781 of September 16, 1985 and the Decree ${ }^{\circ} 98.332$ of 06/15/1998, respectively. As shown in Table 3, a slight reduction occurred in the hourly volume of PE in CE2 (-5 min), whereas the hourly volume increased in CM1 (+ $25 \mathrm{~min})$ and CM2 (+15 min). Since then, there has been a substantial reduction of time in PE in the schools' timetable provided by the Ministry of National Education. As highlighted in Table 3, there is a distinct reduction (between 50 and 80 minutes) in the weekly time allocated to PE from the timetables of 1985 and 1988 to the academic year 2018/19 with only 40 minutes 
being allocated to PE across all grade levels in primary school at this latest year.

\section{Teachers and school principals perception of PE}

Generally, the structure of a PE lesson in Côte d'Ivoire comprises 4 parts: (i) presentation (getting started and putting in situation); (ii) development (setting up teams, identification of the principle and rules of the game, guided practice and objectivities); (iii) application (organization of a mini-competition, conduct of the minicompetition) and (iv) return to calm (gathering of schoolchildren, collection of material, report of the lesson, ranking, return to class in silence).

PE lessons are conducted outdoors, as there are no indoor facilities. While this does not pose any problems during the dry season, PE lessons often come to a stop during the rainy season (May-June). A teacher described this issue as follows:

\footnotetext{
"In any case, during the rainy season, the ground becomes impracticable, there is mud everywhere. We cannot take the risk of sending the children to play in it." (teacher quote from FGDs)
}

As the schools have no groundskeeper, the schoolchildren generally maintain the sports field under the instruction of their teacher (cutting weeds, tracing and sweeping the ground, etc.). This creates a paradoxical situation, since the Ivorian law prohibits the work with sharp objects for children under the age of 12 years. It is further forbidden to allow children to perform certain work activities under penalty of legal proceedings (such as working on farms, cutting weeds, etc.). Under these circumstances, it is not surprising that teaching PE became facultative at many schools.

Teachers at public primary schools in Taabo often have little space available on the school ground to organize PE lessons. While four of the eight involved primary schools have their own sports field for PE lessons, 4 schools have to share the space 
(Table 4). A further challenge towards the space problem is that the national timetable for primary schools allocates PE to the same day and time among two grade levels. As a consequence, the limited school ground has to accommodate two classes at the same time. Yet, schools sharing the space have to accommodate 4 classes on the same sports field (with an average class size of 50 children), making it nearly impractical to provide high quality PE lessons.

In Côte d'Ivoire, the government does not provide sports equipment to the schools (balls, T-shirt etc) to conduct PE. Thus, the school transfers the acquisition costs to the parents, who - in Taabo - have to pay 4,000 FCFA ( US \$ 7) per year and child to the school ( US \$ 0.73 for school equipment and infrastructure, $\sim$ US \$ 1.10 for sport competitions organized between schools by OISSU [Ivorian Office of School and University Sport], US \$ 1.83 to COGES [Secondary Establishment Management Committee] to take care of school infrastructure and US \$ 3.66 for children's school clothes (e.g. T-shirt).

\section{Perceived importance and benefit of teaching PE}

Based on the FGDs, most teachers recognized and highlighted the benefits of PE for the children:

\footnotetext{
"Physical education contributes to the physical and mental development of school children. The youngest schoolchildren in CP1 learn colours and how to orient themselves through physical activities. In the higher-grade levels (CM1 and CM2), PE fosters good health and resilience. The schoolchildren are excited to play sports and therefore, do not want to miss any PE lessons." (teacher quote from FGDs)
}

However, the overall time of 40 minutes is considered too short to actually enable children to develop their full physical capacity and improve their health capital. 
While teachers, on one side, perceived PE as useful and necessary, they, on the other side, deem it less important compared to other subjects that are taught 4-5 hours per week. Some teachers even consider PE to be an optional school subject, because it only takes 40 minutes in the entire weekly schedule. Moreover, PE is often viewed as "play time" rather than a learning opportunity, since there are other possibilities for a child to play during the school day.

\section{Main barriers to teach $P E$}

The fixed time of PE in the weekly timetable is reported by teachers as one of the biggest obstacles to teaching this subject. Presumably to avoid the heat of the day, the Ministry of Education scheduled PE lessons in the morning from 8:00 to 8:40 for CP1 and CM1, and from 9:20 to 10 for CP2 and CM2. However, due to a lack of changing rooms and showers, the children remain sweaty for the next class and rest of the day:

\footnotetext{
"What bothers us is the time at which we must do PE, at the first hour 8h. [...] There are no changing rooms and bathroom so that you can rinse off and change [afterwards], so everyone goes back to class with sweat, dirty body. Anyway, in the classroom, there is an unpleasant smell that emanates from the schoolchildren afterwards and that makes it really uncomfortable to teach, really complicated." (teacher quote from FGDs).
}

Unfortunately, the fixed time in the timetable cannot be changed by the school itself. As mentioned above, the hours are pre-set by the Ministry of National Education, reflecting the vertical relationship between school and the ministry, and leaving little room for individual adaptations. Under these circumstances,

\footnotetext{
"the situation appears as if the state is imposing teaching to teachers without taking into account the conditions under which this teaching takes place" (teacher quote from FGDs).
} 
Yet, putting the unfavourable time aside, a further hindrance to teach PE remains the lack of sanitary facilities to allow for adequate hygiene measures, as well as the care of skin injuries in the course of PE lessons.

Another counter-argument to teach PE comes with the nature of outdoor PE, and the fact that the sports ground is accessible to the general public:

"It's not easy at first, because when we draw [the surrounding lines or boundaries of] the [sports] ground, young people come to play afterwards when we leave, and when we come back, everything is erased and it's a perpetual restart" (teacher quote from FGDs).

Another issue results from the situation where members of the community come to watch the session. As a consequence, PE teachers reported feelings of exposure, in that their actions and gestures are being evaluated by the community; a situation that is perceived negatively.

\footnotetext{
"When we are teaching PE, you see community members watching, as if it is a football match [...]. I can tell you, it's not easy to teach under these circumstances." (teacher quote from FGDs)
}

The lack of grading/marking guidelines on how to assess children's performance in this school subject was identified as further hindrance to teach PE, as explained by this teacher:

\footnotetext{
"In any case, me, who teaches an exam class, I neglect PE a bit, because [...] we evaluate children's performance in relation to what we teach in the classroom, so [...] I treat the marks from their PE performance as a bonus only." (teacher quote from FGDs).
}

Teachers generally perceive school performance as academic performance only. Thus, they evaluate achievements in the classroom and not on the sports field. 
Insufficient infrastructure was repeatedly highlighted by teachers as a major obstacle to implement PE.

"It has become somewhat normal that we do not teach physical education, because even if we are willing to do so, the required conditions are not available" (teacher quote from FGDs).

"When the state builds schools, they do not consider the provision of a space for physical education. Among the basic school kits that the state provides, sports equipment is not part of it." (teacher quote from FGDs)

The inadequate support and infrastructure is therefore seen as an indication of the optional nature of this school subject. This notion is reinforced by the fact that COGES institution (Secondary Establishment Management Committee), which aims to ensure that the required conditions to provide quality education is met (including staff and infrastructure), is not focusing on PE:

\footnotetext{
"And since on an institutional level, the $[\ldots]$ planning of primary school education does not include teaching PE, it cannot sanction a teacher who is not implementing PE." (teacher quote from FGDs)
}

Overall, primary school teachers have gained the impression that if they want to teach PE, it is up to them to find the means to do so. Collectively, we have summarized the main barriers to teach PE in Table 5, including suggestions from stakeholders on how to address them.

\section{Financial appraisal for basic PE facilities and material}

The systematic field observation, followed by the FGDs, have revealed considerable shortfalls regarding the implementation and teaching quality of PE in rural settings (Table 6). To address the main barriers raised above, a cost estimation to equip one primary school with all identified necessities was conducted by stakeholders, including 
costs for a sports field, PE school uniform, hygienic measures, and sports equipment. As shown in Table 6, the minimum amount of 7'649'500 FCFA ( US \$ 14'070) is necessary to ensure the basic infrastructure at one school is met. The overall costs also include the running costs per year of 4'224'000 FCFA ( US \$ 7’769), including those of the parents ( $\sim$ US \$ 15/child) and the government ( $\sim$ US \$ 3'178). The costs for water supply is considered a one-time investment of US \$294), and falls within the responsibility of COGES. Based on experiences from a pilot study carried out with South African primary school children (Gerber et al. 2018), the primary school teachers needed considerable support for the implementation of the PE lessons. Therefore, we have budgeted salary for teacher coaches, who are graduated secondary PE teachers, to support the primary school teachers during the initial stages. This will allow for sufficient capacity building and empowerment of schools to incorporate PE in their given structures and with their own resources. At this stage, teachers would also expect a small financial incentive to get familiar with the lesson plans and implement PE. Both cost positions (teacher coach and teacher incentive) would fall within the responsibility of the government, which is in charge of teacher salary.

In order to ensure that each participating school in the upcoming PE intervention has the necessary requirements to do so, the basic infrastructure and sports equipment, as indicated in Table 6, was provided to all project schools in Taboo.

\section{Discussion}

This is the first situational analysis on the state and status of PE in public primary schools carried out in a typical small to medium sized town in Côte d'Ivoire. The FGDs with local authorities and primary school teachers revealed that teachers are faced with a multitude of barriers including lack of sport equipment and infrastructure, sanitation, sufficient time to reach the health-oriented goals in the PE curriculum as well as criteria 
to assess PE performance. Feeling left alone with these challenges to deal with, teachers are demotivated and unwilling to teach PE.

Most teachers who participated in the FGDs were aware of the benefits that PE holds for school children, such as motor learning and social learning, which is in line with the national syllabus. Yet, few teachers implemented PE. Among the various reasons, a lack of teaching experience was identified. Student teachers receive only a theoretical and practical training module during their initial education at the Centers for Animation and Pedagogical Training (CAPFOP), before starting their professional career at school. Therefore, an investment in further PE fresh-up training (continuous professional development) would be a worthwhile measure. For example in Ghana, where primary school teachers also teach all school subjects, teachers can obtain further training in two or more subjects of choice (Ammah and Kwaw 2005).

However, the reduction of the number of school hours in the schools ' official timetable remains a major concern in Côte d'Ivoire. In favour of academic subjects, such as French, Sciences and Mathematics, the weekly hours allocated to PE were reduced from four lessons of 30 minutes in the foundation classes $(\mathrm{CP} 1, \mathrm{CP} 2)$, and three lessons of 40 minutes in the middle course (CM1, CM2) in 1985 to a single lesson of 40 minutes in 2018. This reduction was implemented despite the authorities' attention on the importance and marginalized situation of PE across West African countries by a UNESCO survey conducted in 2005 (Bini 2016). The situation was exacerbated by a long-running teachers' strike in 2019, after which PE classes were suspended altogether for the benefit of catch-up on academic subjects. Therefore, the findings of the present study are important as they highlight that if the ministry of education does not grant any attention to the subject of PE, primary school teachers are also not motivated to improve their skills in teaching PE. 
The challenges described above are not merely a problem among the country's primary schools, but also observed in secondary schools. In fact, the UNESCO report on the situation of PE among West African countries revealed that the recommended four hours of PE per week by the government are not implemented by the schools. Only one lesson of 2 hours per week was implemented on average (Bini 2016). Outside of Côte d'Ivoire, studies on the situation of PE conducted in Ghana and Nigeria reported a similar trend towards reducing or eliminating weekly PE hours, although the official timetable has dedicated time for PE. However, in Ghana, a significant number of schools use this time for other school subjects or as free periods (Ammah and Kwaw 2005). Similarly, in Nigeria five weekly PE lessons are recommended for both elementary and secondary school, yet, this is rarely practiced in real life (Salokun 2005).

Further barriers to implement PE results from the absence of evaluation guidelines towards children`s performance in PE, particularly for grade 1-5. Several teachers indicated this as a reason to skip this subject. Indeed, PE is only assessed among 6th graders undertaking their final examinations to obtain the Certificate of Primary and Elementary Studies (CEPE). A study done by (Brau-Antony and Cleuzion 2005) on the impact of performance validation in schools, highlights that the meaning goes beyond simply documenting student`s learning and achievement. Data from several countries show that performance validation or grading is also used to strengthen the involvement of teachers, students, and parents in a subject taught at school. Moreover, research on different evaluation contexts shows that summative evaluation is an important step in a child`s learning process (Allain, Lentillon-Kaestner, Voisard, and Deriaz 2015). 
The above outlined problems by the teachers are also seen in other low-to middle income countries outside of Africa. For instance, referring to the situation of PE in Venezuela, Hardman (2008) highlighted the following aspects as key problems: (i) lack of policies for national PE; PE curricula is elaborated, but neither carried out nor up to date to current quality teaching standards of PE; (ii) government contributions are not sufficient; (iii) lack of infrastructure, (iv) lack of sports equipment, (v) lack of resources, facilities and maintenance, and (vi) the time assigned in the curriculum is too short to reach the objectives.

Most of the public schools in Côte d'Ivoire lack proper sport facilities and equipment, while schools receive no contribution by the government for equipment acquisition. In fact, the acquisition of equipment is covered by parents, who have to pay US \$ 7 per academic year and child to the school (US \$ 0.73 school equipment and infrastructure, US \$ 1.10 sport competitions, US \$ 1.83 to GOGES to take care of school infrastructure, and \$ 3.66 for children's school clothes (e.g. T-shirt)). In Taabo, where the majority of parents are farmers, US \$ 7 per child and year is highly expensive. According to recent poverty rates, Côte d'Ivoire ranges in the 39,5\% (Marchat, Treichel, Magassouba 2020; Tape et al. 2005). Unfortunately, the costs that are passed on to the parents are not sufficient to address the lack in sport facilities and equipment, as the necessary minimum amount per school and year totals up to US \$ 17 '637. Ideally, the costs for basic infrastructure and equipment, as well as the annual running costs are split between the government, COGES, and parents. However, with the recent dissolution of COGES by the new government in December 2020, the responsibility to cover the annual investment of approximately US \$10'102 remains unclear at this stage. While the government has claimed the responsibility on regional 
councils, they, in turn, highlight that their budget development for the next year is already completed.

\section{Conclusion}

Teachers at public primary schools in Côte d'Ivoire are responsible to teach all school subjects in the curricula. With regard to PE, teachers are well aware of the importance of regular physical activity for school children's health and cognitive performance. Yet, in practice, little attention is granted to $\mathrm{PE}$ in the general operation of schools, while the PE curriculum itself is poorly implemented. Insufficient time, lack of infrastructure, equipment, and sanitation facilities, along with marginalized teacher training in this subject have been identified as the main barriers to teach PA. To address these barriers, the schools`stakeholders need to adjust the budget for basic infrastructure, the weekly timetable, and assign graduated PE-teacher coaches to each primary school to initiate a fresh-up training to their teachers and guide them in the initial face to empower schools in the long term. To initiate a change to the current state of PE at public primary schools in Côte d'Ivoire, we recommend local stakeholder engagement (parents, teachers, regional council, municipality, INJS, education inspectorate, government, and local NGOs). Thus, empirical evidence is urgently needed in Côte d'Ivoire to proof that regular physical activity and school PE can make an important contributions to children's overall health, learning capacity and wellbeing. 


\section{References}

Allain, M., Lentillon-Kaestner, V., Voisard N., and Deriaz, D. 2015. "Les effets de l'évaluation sommative sur les processus d'enseignement-apprentissage en EPS au degré secondaire I." Rapport Projet NOTEPS. Lausanne : Haute École Pédagogique (HEP-VD): 12.

Ammah, J.O.A.A., Kwaw, N.P 2005. "Physical education in Ghana." (U Pühse, M Gerber, Eds.) In International Comparison of Physical Education. ConceptProblems-Prospects. Oxford : Meyer and meyer sport (UK) Ltd. :311- 327

Bini, K.R. 2016. "Marginalisation de l'éducation physique et sportive dans l'enseignement secondaire en Côte d'Ivoire : cas de lycées et collèges de la commune d'Abobo " Thèse de Doctorat, Université Félix Houphouët-Boigny de Cocody, Abidjan:318.

Brau-Antony, S and Cleuzion J.P. 2005. "L'évaluation en EPS. Concepts et contributions actuelles." Les carnets Actio. Paris : Éd. Actio, cop. :158.

Couturier, L., Chepko S., Hale S. 2014. "National standards \&grade-level outcomes for K-12 physical education." Shape America \& Human Kinetics:46.

Donnelly JE, Hillman CH, Castelli D, Etnier JL, Lee S, Tomporowski P, Lambourne K, Szabo-Reed AN. 2016. "Physical Activity, Fitness, Cognitive Function, and Academic Achievement in Children: A Systematic Review." Med Sci Sports Exerc 48 (6):1197-222. doi: 10.1249/MSS.0000000000000901.

Etnier, Benjamin A. Sibley and Jennifer L. 2003. "The relationship between physical activity and cognition in children: A meta-analysis." Pediatric Exercise Science 15 (3):243-256. doi: 10.1515/ijsl.2000.143.183.

Gall, S., Walter, C., du Randt, R., Adams, L., Joubert, N., Müller, I., Nqweniso, S., Pühse, U., Seelig, H., Smith, D., Steinmann, P., Utzinger, J., \& Gerber, M. . 2020. "Changes in Self-Reported Physical Activity Predict Health-Related Quality of Life Among South African Schoolchildren: Findings From the DASH Intervention Trial." Frontiers in public health 8: 492618. doi: https://doi.org/10.3389/fpubh.2020.492618.

Gerber M, Ayekoé SA, Beckmann J, Bonfoh B, Coulibaly JT, Daouda D, du Randt R, Finda L, Gall S, Mollel GJ, Lang C, Long KZ, Ludyga S, Masanja H, Müller I, Nqweniso S, Okumu F, Probst-Hensch N, Pühse U, Steinmann P, Traoré SG, Walter C, Utzinger J. 2020. "Effects of school-based physical activity and multi- 
micronutrient supplementation intervention on growth, health and well-being of schoolchildren in three African countries: the KaziAfya cluster randomised controlled trial protocol with a $2 \times 2$ factorial design " Trials 21 (22):1-17. doi: 10.1186/s13063-019-3883-5.

Gerber M, Müller I, Walter C, du Randt R, Adams L, Gall S, Joubert N, Nqweniso S, Smith D, Steinmann P, Probst-Hensch N, Utzinger J, Pühse U. 2018. "Physical activity and dual disease burden among South African primary schoolchildren from disadvantaged neighbourhoods." Prev Med 112:104-110. doi: 10.1016/j.ypmed.2018.04.001.

Global Partnership for Education (GPE). 2018. "Summative Evaluation of GPE's Country-level Support to Education." Report Universalia Management Group 245 Victoria Avenue, Suite 200 Westmount, Montreal, Quebec Canada H3Z 2M6:148.Hoque, Enamul M. 2016. "Three Domains of Learning: Cognitive, Affective and Psychomotor." The Journal of EFL Education and Research (JEFLER), 2:45-52.

Kempermann, Gerd. 2008. "The neurogenic reserve hypothesis: what is adult hippocampal neurogenesis good for?" Trends in Neurosciences 31 (Issue 4):163-169. doi: https://doi.org/10.1016/j.tins.2008.01.002.

Ken Hardman. 2008. "Situation and sustainability of physical education in schools: A global perspective." Spor Bilimleri Dergisi Hacettepe J. of Sport Sciences 19 (1): $1-22$

doi: 10.1.1.608.2737.

Koné S, Baikoro N, N'Guessan Y, Jaeger FN, Silué KD, Fürst T, Hürlimann E, Ouattara M, Séka MC, N'Guessan NA, Esso EL, Zouzou F, Boti LI, Gonety PT, Adiossan LG, Dao D, Tschannen AB, von Stamm T, Bonfoh B, Tanner M, Utzinger J, N'Goran EK. . 2015. "Health \& Demographic Surveillance System Profile: The Taabo Health and Demographic Surveillance System, Côte d'Ivoire." Int J Epidemiol 44 (1):87-97. . doi: 10.1093/ije/dyu221.

Ludyga S, Gerber M, Brand S, Holsboer-Trachsler E, Pühse U. 2016. "Acute effects of moderate aerobic exercise on specific aspects of executive function in different age and fitness groups: A meta-analysis." Psychophysiology. 53 (11):16111626. doi: 10.1111/psyp.12736.

Ludyga S, Gerber M, Pühse U, Looser VN, Kamijo K. 2020. "Systematic review and meta-analysis investigating moderators of long-term effects of exercise on 
cognition in healthy individuals." Nat Hum Behav 4 (6):603-612. doi: 10.1038/s41562-020-0851-8.

Macpherson H, Teo WP, Schneider LA, Smith AE. 2017. "A Life-Long Approach to Physical Activity for Brain Health." Front Aging Neurosci 23 (9):147. doi: 10.3389/fnagi.2017.00147.

Marchat, J.M., Treichel V., et Magassouba M. 2020. "Le Diagnostic du Secteur Privé en Côte d'Ivoire. Créer des marchés en Côte d'Ivoire. Mobiliser le secteur privé pour appuyer la transformation économique de la Côte d'Ivoire." Rapport de la Société Financière Internationale (SFI), membre du Groupe de la Banque mondiale 19.

Martyniuk, O.J., Tucker, P. 2014. "An exploration of Early Childhood Education students $\$ knowledge and preparation to facilitate physical activity for preschoolers: a cross-sectional study." BMC Public Health 14:727. doi: https://doi.org/10.1186/1471-2458-14-727.

Müller, I., Schindler, C., Adams, L., Endes, K., Gall, S., Gerber, M., Htun, N., Nqweniso, S., Joubert, N., Probst-Hensch, N., du Randt, R., Seelig, H., Smith, D., Steinmann, P., Utzinger, J., Yap, P., Walter, C., \& Pühse, U. 2019. "Effect of a Multidimensional Physical Activity Intervention on Body Mass Index, Skinfolds and Fitness in South African Children: Results from a ClusterRandomised Controlled Trial." Int J Environ Res Public Health 16 (2):232. doi: 10.3390/ijerph16020232. .

Oberlack C., Breu T., Giger M., Harari N., Herweg K., Mathez-Stiefel S., Messerli P., Moser S., Ott C., Providoli I., Tribaldos T., Zimmermann A., Schneider F. 2019. "Theories of change in sustainability science: Understanding how change happens." GAIA - Ökologische Perspektiven für Wissenschaft und Gesellschaft / ecological perspectives for science and society 28 (2):106 -111. doi: 10.14512/gaia.28.2.8.

Salokun, SO. 2005. "Physical education in Nigeria." (U Pühse, M Gerber, Eds.). In International Comparison of Physical Education. Concept-Problems-Prospects. Oxford : Meyer and meyer sport (UK) Ltd. : 497-511. .

Salvini M, Gall S, Müller I, Walter C, du Randt R, Steinmann P, Utzinger J, Pühse U, Gerber M. 2018. "Physical activity and health-related quality of life among schoolchildren from disadvantaged neighbourhoods in Port Elizabeth, South Africa." Qual Life Res 27 (1):205-216. doi: 10.1007/s11136-017-1707-1. 
Tape, C., Samassi D., Yao N. Jonas., Deza D.A., Ba Z.S., Yao K. E., Boti B.B.., Toure A., Yao K.H., Gue T. A. M, Abou T.H., Goh Y.E. 2005. "Enquête sur le niveau de vie des ménages en Côte d'Ivoire." National report:19.

Traoré, S.G., Fokou, G., Ndour, A.P.N., Yougbare, B., Koné, P., Alonso, S., Roesel, K., Bakou, S.N., Dao, D., Grace, D. and Bonfoh, B. 2018. "Assessing knowledge, beliefs and practices related to the consumption of sheep and goat meat in Senegal." Global Food Security 19:64-70. doi: https://doi.org/10.1016/j.gfs.2018.10.001.

Trudeau, F., Shephard, R.J. 2008. "Physical education, school physical activity, school sports and academic performance." Int J Behav Nutr Phys A 5 (10):1-12. doi: https://doi.org/10.1186/1479-5868-5-10.

Walter, C.M., Du Randt, R. \& Venter, D.J.L. 2011. "The physical activity and health status of two generations of Black South African professional women." Health SA Gesondheid 16 (1):1-9. doi: 10.4102/hsag.v16i1.538.

WHO, 2020. Physical activity.https://www.who.int/news-room/factsheets/detail/physical-activity. 


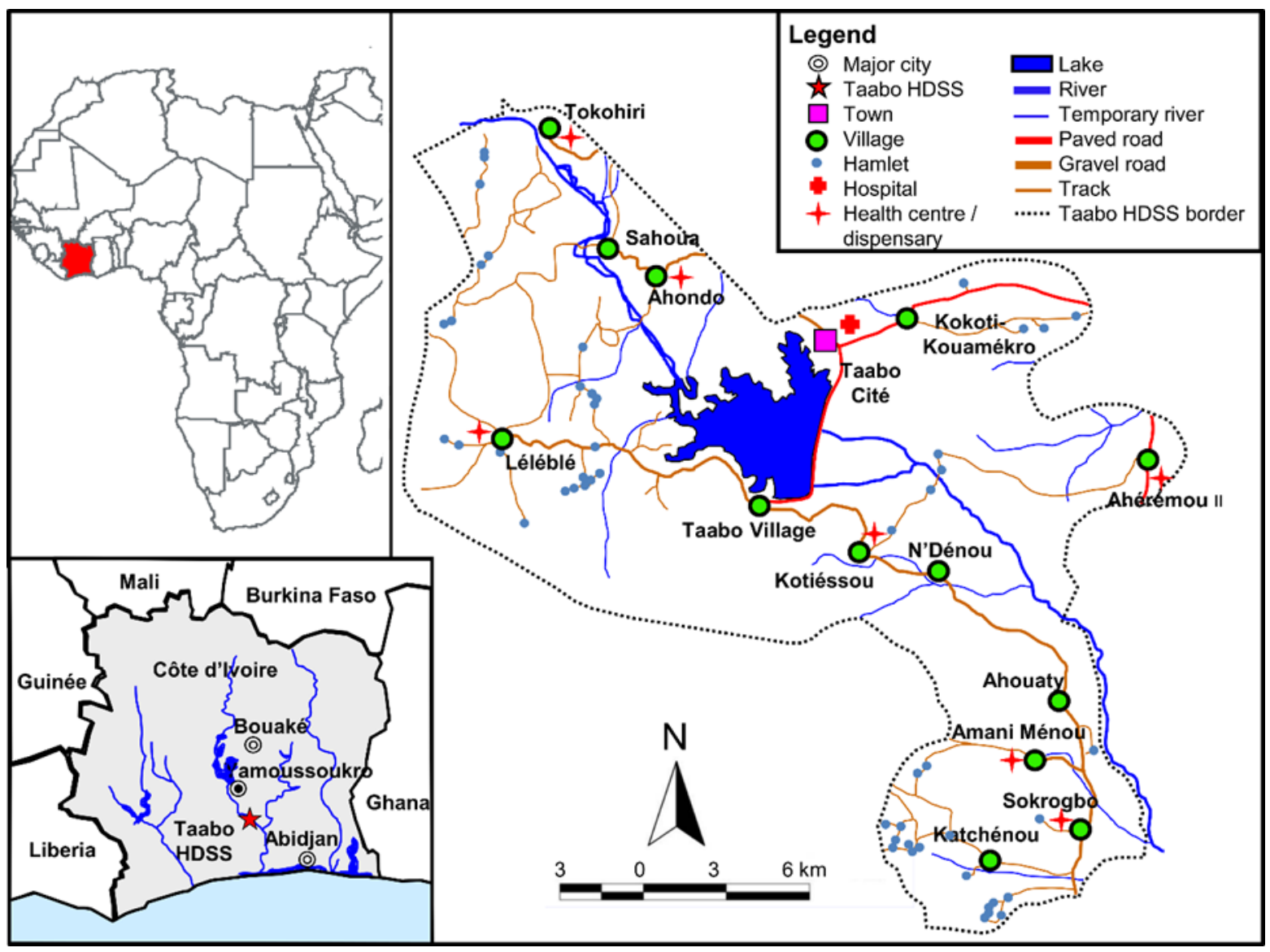

Figure 1: Geographical location of Taabo in Côte d'Ivoire (Koné et al., 2014) 
Table 1: Time allocated to school subject in grade 1 (CP1) for the academic year $2018 / 19$

\begin{tabular}{lll}
\hline Lessons & $\begin{array}{l}\text { Total time per } \\
\text { week (min) }\end{array}$ & $\begin{array}{l}\text { of total } \\
\text { minutes per } \\
\text { week }\end{array}$ \\
& & 52 \\
\hline $\begin{array}{l}\text { French (oral expression, written expression, } \\
\text { grammar, spelling, vocabulary, reading) }\end{array}$ & 865 & 38 \\
Mathematics and sciences & 625 & 2,7 \\
Physical education (PE) & 45 & 2,4 \\
Expression and creation activities (AEC) & 40 & 2,1 \\
Education in human rights and citizenship & 35 & 1,3 \\
(EDHC) & & 25 \\
Singing & 30 & 1,5 \\
Civic act (salute to the national flag) & & \\
\hline
\end{tabular}


Table 2: Time allocated to each school subject in grade 1 (CP1) for the academic year $2019 / 2020$

\begin{tabular}{lll}
\hline Lessons & $\begin{array}{l}\text { Total time per } \\
\text { week (min) }\end{array}$ & $\begin{array}{l}\text { minutes per } \\
\text { week }\end{array}$ \\
& & 52 \\
\hline $\begin{array}{l}\text { French (oral expression, written expression, } \\
\text { grammar, spelling, vocabulary, reading) }\end{array}$ & 865 & 38 \\
Mathematics and sciences & 625 & 2,4 \\
Physical education (PE) & 40 & 2,7 \\
Expression and creation activities (AEC) & 45 & 2,1 \\
Education in human rights and citizenship EDHC) & 35 & 1,3 \\
Singing & 25 & 1,5 \\
Civic act (salute to the national flag) & 30 & \\
\hline
\end{tabular}


Table 3: Time allocated to PE per grade in 1985 and 1988

\begin{tabular}{|c|c|c|c|}
\hline Year & Grade & $\begin{array}{l}\text { Number of weekly PE sessions / duration } \\
\text { of session }\end{array}$ & $\begin{array}{l}\text { Total time per } \\
\text { week }\end{array}$ \\
\hline \multirow[t]{3}{*}{1985} & $\mathrm{CP} 1$ and $\mathrm{CP} 2$ & 4 sessions of $30 \mathrm{~min}$ & $2 \mathrm{~h}$ \\
\hline & CE1 and CE2 & 3 sessions of $40 \mathrm{~min}$ & $2 \mathrm{~h}$ \\
\hline & $\mathrm{CM} 1$ and $\mathrm{CM} 2$ & 2 sessions of 45 minutes & $1 \mathrm{~h} 30 \mathrm{~min}$ \\
\hline \multirow[t]{3}{*}{1988} & $\mathrm{CP} 1, \mathrm{CP} 2$ and $\mathrm{CE} 1$ & 3 sessions of $40 \mathrm{~min}$ & $2 \mathrm{~h}$ \\
\hline & CE2 and CM1 & 3 sessions of $40 \mathrm{~min}, 35 \mathrm{~min}$ and $40 \mathrm{~min}$ & $1 \mathrm{~h} 55 \mathrm{~min}$ \\
\hline & $\mathrm{CM} 2$ & 3 sessions of $35 \mathrm{~min}, 30 \mathrm{~min}$ and $40 \mathrm{~min}$ & 1 hour $45 \mathrm{~min}$ \\
\hline $2018 / 2019$ & $\mathrm{CP} 1$ to $\mathrm{CM} 2$ & 1 session of $40 \mathrm{~min}$ & $40 \mathrm{~min}$ \\
\hline
\end{tabular}


Table 4: Size of sport field and number of school children (boys and girls) per school

\begin{tabular}{|c|c|c|c|c|}
\hline School & $\begin{array}{l}\text { Average N } \\
\text { children / class }\end{array}$ & $\begin{array}{l}\text { N boys / } \\
\text { school }\end{array}$ & $\begin{array}{l}\text { N girls / } \\
\text { school }\end{array}$ & Size of schools sports field \\
\hline Barrage 1 & 52 & 155 & 157 & $\begin{array}{l}\mathrm{L}: 40 \mathrm{~m} ; \mathrm{W}: 20 \mathrm{~m} \text { (one } \\
\text { football ground of } 800 \mathrm{~m} 2 \text { ) } \\
\mathrm{L}: 20 \mathrm{~m} ; \mathrm{W}: 15 \mathrm{~m} \text { (one } \\
\text { handball ground of } 300 \mathrm{~m} 2 \text { ) }\end{array}$ \\
\hline Barrage 3 & 37 & 127 & 109 & $\begin{array}{l}\mathrm{L}: 40 \mathrm{~m} ; \mathrm{W}: 30 \mathrm{~m} \text { (one } \\
\text { handball ground of } 1200 \\
\mathrm{~m} 2)\end{array}$ \\
\hline & & & & $\begin{array}{l}\mathrm{L}: 30 \mathrm{~m} ; \mathrm{W}: 20 \mathrm{~m} \text { (one } \\
\text { handball ground of } 600 \mathrm{~m} 2 \text { ) }\end{array}$ \\
\hline Barrage 4 & 41 & 117 & 130 & $\begin{array}{l}\mathrm{L}: 40 \mathrm{~m} ; 120 \mathrm{~m} \text { (one football } \\
\text { ground of } 800 \mathrm{~m} 2 \text { ) }\end{array}$ \\
\hline EECI & 36 & 111 & 108 & $\begin{array}{l}\mathrm{L}: 40 \mathrm{~m} ; \mathrm{W}: 20 \mathrm{~m} \text { (one } \\
\text { football ground of } 800 \mathrm{~m} 2 \text { ) } \\
\mathrm{L}: 20 \mathrm{~m} ; \mathrm{W}: 15 \mathrm{~m} \text { (one } \\
\text { handball ground of } 300 \mathrm{~m} 2 \text { ) }\end{array}$ \\
\hline Municipal & 30 & 92 & 88 & $\begin{array}{l}\mathrm{L}: 40 \mathrm{~m} ; \mathrm{W}: 20 \mathrm{~m} \text { (one } \\
\text { football ground of } 800 \mathrm{~m} 2 \text { ) }\end{array}$ \\
\hline Village 1 & 38 & 106 & 117 & $\begin{array}{l}\mathrm{L}: 40 \mathrm{~m} ; \mathrm{W}: 30 \mathrm{~m} \text { (one } \\
\text { football ground of } 1200 \\
\mathrm{~m} 2 \text { ) }\end{array}$ \\
\hline & & & & $\begin{array}{l}\mathrm{L}: 30 \mathrm{~m} ; \mathrm{W}: 20 \mathrm{~m} \text { (one } \\
\text { handball ground of } 600 \mathrm{~m} 2 \text { ) }\end{array}$ \\
\hline
\end{tabular}

Notes: L=Length, W=Width. 
Table 5: Main barriers to teach physical education and how to address them

\begin{tabular}{|c|c|c|c|c|}
\hline Problem & Activities & Outputs & Outcomes & Desired situation \\
\hline $\begin{array}{l}\text { The time } \\
\text { allocated to PE is } \\
\text { insufficient to } \\
\text { substantially } \\
\text { increase physical } \\
\text { activity levels and } \\
\text { literacy }\end{array}$ & $\begin{array}{l}\text { Negotiation with } \\
\text { the inspection of } \\
\text { Taabo }\end{array}$ & $\begin{array}{l}\text { Insisting on } \\
\text { implementing the } \\
\text { compulsory } \\
\text { minimum of } 40 \\
\text { min PE/week. } \\
\text { Requesting an } \\
\text { additional PE } \\
\text { unit/week }\end{array}$ & $\begin{array}{l}\text { Developing the } \\
\text { culture of sport }\end{array}$ & $\begin{array}{l}\text { Increasing time } \\
\text { allocated to PE } \\
\text { minimum of } 40 \\
\text { min PE, } 3 \text { times } \\
\text { /week. }\end{array}$ \\
\hline $\begin{array}{l}\text { Lack of teaching } \\
\text { experience and } \\
\text { training for } \\
\text { Teachers }\end{array}$ & $\begin{array}{l}\text { Recruitment of of } \\
\text { supporting } \\
\text { coaches }\end{array}$ & $\begin{array}{l}\text { Assigning sport } \\
\text { coaches to support } \\
\text { primary school } \\
\text { teacher }\end{array}$ & $\begin{array}{l}\text { Developing the } \\
\text { culture of sport }\end{array}$ & $\begin{array}{l}\text { Providing } \\
\text { Refresher courses } \\
\text { on PE to teachers }\end{array}$ \\
\hline $\begin{array}{l}\text { Lack of sport } \\
\text { facilities }\end{array}$ & $\begin{array}{l}\text { Field upgrading } \\
\text { (more space) } \\
\text { Supply of } \\
\text { equipment } \\
\text { (football balls, } \\
\text { handballs, tennis } \\
\text { balls, skipping } \\
\text { rope...) }\end{array}$ & $\begin{array}{l}\text { Sufficient sports } \\
\text { equipment } \\
\text { Provision of } \\
\text { hygiene kits to } \\
\text { schools and the } \\
\text { inspectorate to } \\
\text { fight COVID-19 }\end{array}$ & $\begin{array}{l}\text { Developing the } \\
\text { culture of sport } \\
\text { Security } \\
\text { Hygiene }\end{array}$ & $\begin{array}{l}\text { Investment of } \\
\text { government in } \\
\text { basic sport } \\
\text { facilities with } \\
\text { changing rooms } \\
\text { to improve } \\
\text { hygiene } \\
\text { Access to water } \\
\text { Changing room } \\
\text { maintenance with } \\
\text { the involvement } \\
\text { of managers } \\
\text { Involvement of } \\
\text { parents by } \\
\text { purchasing sports } \\
\text { uniforms }\end{array}$ \\
\hline
\end{tabular}

Notes: INJS = Institut National de la Jeunesse et du sport. WASH $=$ Water Sanitation, and Hygiene. 
Table 6: Estimated costs (US \$) for sports equipment and staff costs to provide physical education at one primary school with an average class size of 50 children in Taabo

\begin{tabular}{|c|c|c|c|c|c|c|c|c|}
\hline Items & Descriptions & Qty & Unit cost & Total cost & Annual rC & $\begin{array}{l}\text { Investment } \\
{ }^{a} \text { COGES }\end{array}$ & $\begin{array}{l}\text { Cost for } \\
\text { family }\end{array}$ & $\begin{array}{c}\text { Cost for } \\
\text { Government }\end{array}$ \\
\hline \multicolumn{9}{|l|}{ Basic infrastructure } \\
\hline Football ground & Size and surface upgrading school ground & 1 & 184 & 184 & - & 184 & - & - \\
\hline Handball ground & Size and surface upgrading school ground & 1 & 92 & 92 & - & 92 & - & - \\
\hline Metal poles & & 2 & 368 & 736 & - & 736 & - & - \\
\hline Changing rooms & for boys and girls, including shower & 2 & $1^{\prime} 839$ & 3'679 & - & 3'679 & - & - \\
\hline Water connection & & 1 & 294 & 294 & - & 294 & - & - \\
\hline Total basic equipment & & 1 & 2'777 & $4^{\prime} 984$ & - & $4^{\prime} 984$ & - & - \\
\hline 5-year amortization & & & 938 & 938 & - & - & - & - \\
\hline \multicolumn{9}{|l|}{ Operation } \\
\hline \multicolumn{9}{|l|}{ Sports equipment } \\
\hline Tennis ball & & 50 & 4 & 184 & - & 184 & - & - \\
\hline Football & & 12 & 9 & 110 & - & 110 & - & - \\
\hline Handball & & 12 & 6 & 66 & - & 66 & - & - \\
\hline Cones & Pack of 40 & 1 & 37 & 37 & - & 37 & - & - \\
\hline Jumping rope & & 50 & 9 & 460 & - & 460 & - & - \\
\hline Hoops & & 25 & 6 & 161 & - & 161 & - & - \\
\hline Whistle & For each teacher & 6 & 4 & 22 & - & 22 & - & - \\
\hline Stopwatch & For each teacher & 6 & 46 & 276 & - & 276 & - & - \\
\hline \multicolumn{9}{|l|}{ Staff } \\
\hline Salary of coaches & 1 hour*school weeks*2 coaches & 72 & 41 & $2^{\prime} 980$ & $2^{\prime} 980$ & - & - & 2'980 \\
\hline Salary teachers & Incentive : $1^{*}$ hour/week*6 teachers*12 months & 72 & 3 & 199 & 199 & - & - & 199 \\
\hline \multicolumn{9}{|l|}{ PE school uniform } \\
\hline T-shirts & for 50 students/class across 6 grade levels & 300 & 3 & 828 & 828 & - & 828 & - \\
\hline Shorts & for 50 students/class across 6 grade levels & 300 & 3 & 828 & 828 & - & 828 & - \\
\hline Shoes & for 50 students/class across 6 grade levels & 300 & 6 & $1^{\prime} 655$ & $1^{\prime} 655$ & - & $1^{\prime} 655$ & - \\
\hline \multicolumn{9}{|l|}{ Hygiene } \\
\hline Water & Water supply and consumption*12 months & 4 & 55 & 221 & 221 & - & 221 & - \\
\hline Liquid soap (5 L) & $1 \times 5$ L per class $* 6$ grades $* 12$ months & 72 & 9 & 662 & 662 & - & 662 & - \\
\hline Hand sanitizer & $2 \times 500 \mathrm{ml}$ per class $* 6$ grades $* 12$ months & 144 & 3 & 397 & 397 & - & 397 & - \\
\hline Total Operation & & & 243 & 9’085 & 7'769 & 1’316 & 4'591 & 3'178 \\
\hline Total & & & 3'020 & $14^{\prime} 070$ & 7'769 & 6,300 & 4'591 & 3'178 \\
\hline
\end{tabular}

Notes. Annual $\mathrm{rC}=$ annual recurrent costs. ${ }^{\mathrm{a} C O G E S}=$ Secondary Establishment Management Committee, which is responsible for infrastructure. Yet, the committee was 